\title{
THE SIMULATION OF GRANULAR PARTICLE ON DRY AND MOISTURIZED POROUS HORIZONTAL SURFACES
}

\author{
Dewi Muliyati ${ }^{1, *}$, Dadan Sumardani ${ }^{2}$, Fauzi Bakri ${ }^{1}$, Handjoko Permana ${ }^{1}$, \\ Erfan Handoko ${ }^{3}$, Ni Larasati Kartika Sari ${ }^{4}$ \\ ${ }^{1}$ Physics Education Department, Universitas Negeri Jakarta, Jakarta, Indonesia \\ ${ }^{2}$ Teachers College, National Chiayi University, Taiwan \\ ${ }^{3}$ Physics Department, Universitas Negeri Jakarta, Jakarta, Indonesia \\ ${ }^{4}$ Physics Department, Universitas Nasional, Jakarta, Indonesia \\ *Corresponding Author Email: dmuliyati@unj.ac.id
}

Received: 10 January 2021

Revised: 24 March 2021

Accepted: 2 April 2021

Online: 30 April 2021

Published: 30 April 2021

SPEKTRA: Jurnal Fisika dan Aplikasinya p-ISSN: 2541-3384

e-ISSN: 2541-3392

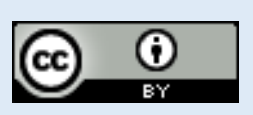

\begin{abstract}
Simulations were carried out to visualize the ratio of granular attachment to porous surfaces. This simulation uses a uFlex threedimensional simulation using three sizes of porous surface systems in the condition of the smallest human pores and the most extensive human pores and the condition of wet skin and dry skin. Each system was tested using five granular particle sizes according to the range of the makeup granules' size to determine the optimal adhesive. The results show that the number of cosmetic granular particles entering the porous surface system is directly proportional to the porous surface volume and moisture and inversely proportional to the granular cosmetic size. The larger the cosmetic granular used, the less granular enters the pore.
\end{abstract}

Keywords: dry surface, granular simulation, moisturized surface, porous horizontal surfaces 


\section{INTRODUCTION}

The development of simple particle geometry simulations has been carried out in analyzing granular material [1]. Granular particle simulation is done by neglecting the effect of microscale geometric configuration on the macroscopic scale response. The mechanical behavior of granular particles is generally studied by considering the contact properties of the particles that occur [2].

Preliminary research has been carried out, including numerical simulation techniques using the discrete element method (DEM) to analyze the undrained shear behavior of sand containing dissociated hydrate gas [3], characteristics of the internal flow structure of microscopic movements of coarse particles in the pipe [4], and simulate the dispersion process of active pharmaceutical ingredients (API) after collision with powder inhalers used for healing lungs [5].

Granular computing is inspired by structured thinking, structured problem solving, and structured information processing [6]. The wide distribution of data, simulations, and complexity makes granular computing seen as an interdisciplinary study of computing. The granular computing system will produce valuable identification into the underlying macroscopic structure of the granular system [7].

This research simulated a granular system on the application of cosmetics to porous surfaces. A porous surface is intended as a simple form of visualization of pores in humans. Pores can be enlarged in size and amount based on exposure to sunlight and lifestyle, which is an open problem for the skin [8]. The size of cosmetics in the market is very diverse and is taken as samples in the diameter range of 1 to $3 \mu \mathrm{m}$ [9-11]. Recently there has also been an interest in the presence of nanoparticles in products such as cosmetics, which are under $100 \mathrm{~nm}$ [10], [12]. Some techniques only report the center point and distribution. Others provide greater detail throughout the detected upper and lower particle sizes. The distribution of particle size can be calculated based on several models: most often as a number or volume/ mass distribution [10]. The sample pores are pores in the human face area (scalp not included) with comparable densities (i.e., 200-300/ $\mathrm{cm}^{2}$ ), have different sizes, and have a diameter of about 5$10 \mu \mathrm{m}[8,13]$.

Besides, this study also simulates the use of cosmetics on dry and moist skin types. Moist skin means healthy skin, where the balance between sebum and lipids is balanced. The skin will have a natural system for storing water in or on the skin [14]. The primary purpose of developing moisturizers is to restore lipids to the surface of the skin after cleaning.

Granular attachment simulation will be analyzed using sphere packing with a random close pack system. Sphere packing is the determination of the composition of the densest particles that do not go out of space and reach a maximum density of $\varphi$. The random packing of equal spheres generally has a packings fraction $\varphi \approx 0.64$ [15].

A granular attachment on a porous surface will have a rule, the same as attaching a sphere to a big sphere. However, in this simulation, we use a sphere inside a half prolate spheroid (pore shape). The determination of packing square to the big square even began to be developed long time ago [16], same as packing spheres into cylinder [17], but in this research, we discuss 
small spheres in big sphere [18]. In this research, the simulation is carried out to find out the effect of attaching the granular system to dry and moisturized surfaces. These results are expected to be a reference in subsequent studies.

\section{MATERIALS AND METHODS}

Every particle in the system acts as a rigid body and will not break, reflecting the properties of the indestructible cosmetic component. The particle size distribution curve is shown in FIGURE 1, with a grain diameter of $1-5 \mu \mathrm{m}$. The granular used is categorized as coarse to fine granular for cosmetic purposes.
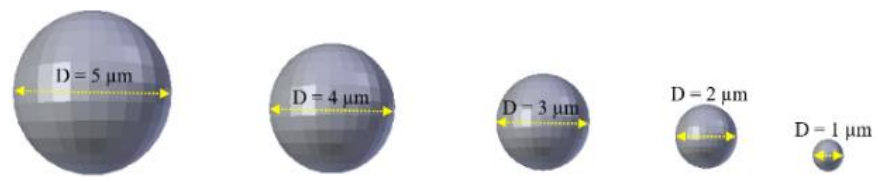

FIGURE 1. Particle Size Distribution

The coefficient of friction between particles in this simulation was identified as 0.5. The condition of the restitution coefficient is assumed on the porous surface and on each particle, equal to 0.1 . The numerical samples of each granular grain had various diameters and contained 32768 particles.

\section{DEM Model}

DEM simulation has been used to investigate cosmetic behavior in the process of shipping from manufacturing to natural antioxidant skin [12], simulation of skin aging and wrinkle as a cosmetic reference [19], simulating makeup by manipulating the actual appearance using appropriate cosmetics [20], simulation to get an understanding more deeply about exposure to particles and droplets in the air during the application of cosmetic products [21], Xu \& Song studied the undrained sliding behavior of sand containing dissociated hydrate gas [3], Ting \& Xinzhou understand the internal flow structure characteristics of microscopic movements of coarse particles in pipes [4], and Ariane \& Sommerfeld simulates the process of collision of inhalers powder used for lung healing [5].

The Falling Granular Volume of Powder is identified based on EQUATION 1. Where the granular is seen as a perfect ball. At the same time, the overall volume of $V_{\text {Cosmetis }}$ cosmetics is the product of the volume of $V_{\text {Granular }}$ granules multiplied by the total amount of granular $N_{G}$.

$V_{\text {Granular }}=\frac{4}{3} \pi r^{3}$

$V_{\text {Cosmetic }}=\frac{4}{3} \pi r^{3} \cdot N_{G}$

Based on these equations, we can identify the granular volume $V_{\text {Granular }}$ and the cosmetic volume $V_{\text {Cosmetic. }}$ These results are identified in TABLE 1 . A total of $1.7 \times 10^{4}-2.1 \times 10^{6} \mu \mathrm{m}^{3}$ samples of cosmetics were evenly sprinkled on this simulation on a porous surface. When sprinkled on a porous surface, a packing process occurs in each pore.

A large collection of non-overlapping solid (particle) solids in the Euclidean space Ddimensional $R^{d}$ called packing. The packing density $\varphi$ is defined as the fraction of $R^{d}$ space 
covered by the particles. The problem that has been a source of attraction for mathematicians and scientists for centuries is the determination of the densest arrangement of particles that do not go out of space and reach a maximum density of $\varphi$ [22]. Packing the sphere shape $\varphi$ can be reviewed in TABLE 2 .

TABLE 1. List of Volume

\begin{tabular}{lllll}
\hline Pore Type & $\mathrm{r}(\mu \mathrm{m})$ & $\mathrm{V}_{\text {Granular }}\left(\mu \mathrm{m}^{3}\right)$ & $\mathrm{N}_{\mathrm{G}}$ & $\mathrm{V}_{\text {Cosmetic }}\left(\mu \mathrm{m}^{3}\right)$ \\
\hline $1 \mu \mathrm{m}$ & 0.5 & 0.5238 & 32768 & 17164.19 \\
$2 \mu \mathrm{m}$ & 1.0 & 4.1905 & 32768 & 137313.52 \\
$3 \mu \mathrm{m}$ & 1.5 & 14.1428 & 32768 & 463433.14 \\
$4 \mu \mathrm{m}$ & 2.0 & 33.5238 & 32768 & 1098508.19 \\
$5 \mu \mathrm{m}$ & 2.5 & 65.4762 & 32768 & 2145523.81 \\
\hline
\end{tabular}

TABLE 2. The Comparison of Various Modes of Sphere Packing [23].

\begin{tabular}{|c|c|c|c|}
\hline Model & Description & Bulk porosity & Packing density \\
\hline Thinnest regular packing & The cubic & 0.4764 & 0.5236 \\
\hline Very loose random packing & $\begin{array}{l}\text { When the fluid velocity is slowly } \\
\text { reduced in a fluidized bed }\end{array}$ & 0.44 & 0.56 \\
\hline Loose random packing & by individual random hand-packing & 0.40 and 0.41 & 0.59 and 0.60 \\
\hline Poured random packing & Spheres are poured into a container & 0.375 to 0.391 & 0.609 to 0.625 \\
\hline Close random packing & $\begin{array}{l}\text { The bed is vibrated or shaken down } \\
\text { vigorously }\end{array}$ & 0.359 to 0.375 & 0.625 to 0.641 \\
\hline Densest regular packing & The rhombohedral & 0.2595 & 0.7405 \\
\hline
\end{tabular}

Based on the TABLE 2, for equal spheres in three dimensions, the densest packing uses approximately $74 \%$ of the volume. For equal spheres, it has only recently been proved that the rhombohedral lattice has the highest possible packing fraction [22,24]. Random packing of equal spheres generally has a packings fraction $\varphi \approx 0.64$ [25]. Based on the theory, a simulation using a random packing sphere was carried out with packings fraction $\varphi \approx 0.64$ and 32768 granular. Furthermore, the granular attachment will be analyzed in each pore using simulation and compared with the results of the calculation.

\section{Skin Pores as Horizontal Surfaces}

Pores are holes of the sebaceous glands and sweating that widens on the surface of the skin. Sebaceous glands have lobular structures, and their size varies from one region to another [25]. Skin appearance, when viewed perpendicularly, will consist of several appearances, namely wrinkles, pores, moles, and spots covering it [25]. The state of the porous surface system is made in such a way as to match the state of the pores of the human skin. The human pore is illustrated in FIGURE 2.

In this simulation, three porous cross-sections will be made, which are assumed to be pores on human skin. The diameter of each porous hole is an interpretation of the minimum, middle, and maximum diameter of a human pore. The $3 \mathrm{D}$ volume dimension of the pores can be determined using the ellipse flat-plane equation identification, which is then rotated to the yaxis. Then the equation is simulated using DESMOS software [27], and a flat field ellipse simulation is produced in FIGURE. 4. Then the desired ellipsoid prolate will be formed when the $y$ axis is rotated at $360^{\circ}$. The ellipsoid prolate equation in the 3-dimensional plane in the large pores (EQ. 3), medium pores (EQ. 4), large pores (EQ. 5) were formulated. The form of 
the prolate ellipsoid is formed as FIGURE 3. The prolate ellipsoid formed was then simulated using GeoGebra software.

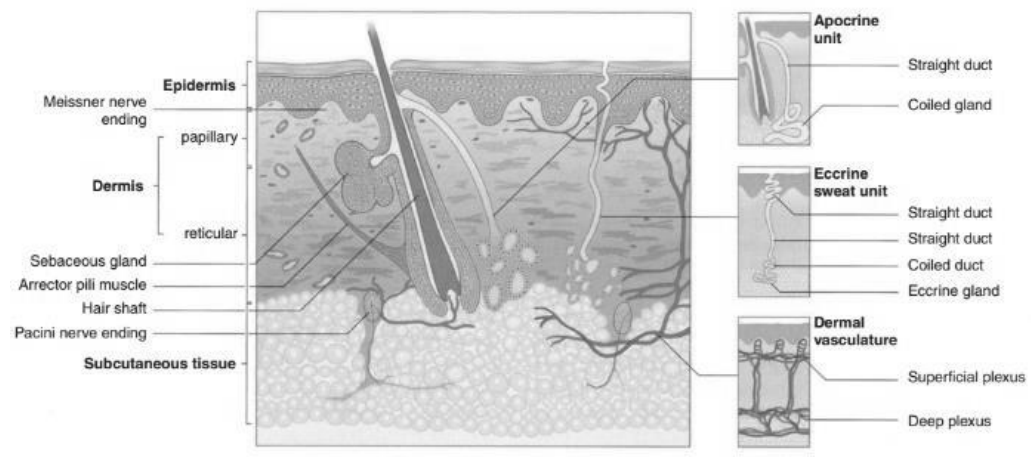

FIGURE 2. Skin surface through side view [26].

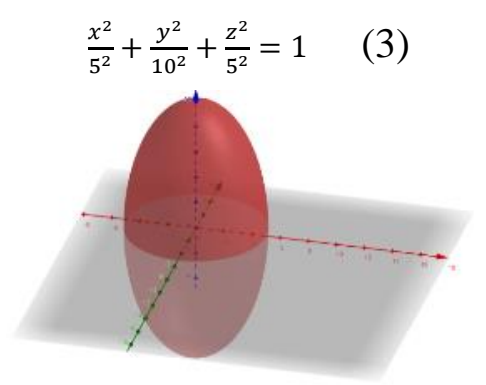

(a)

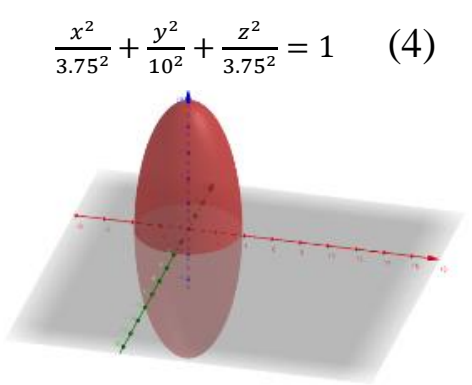

(b)

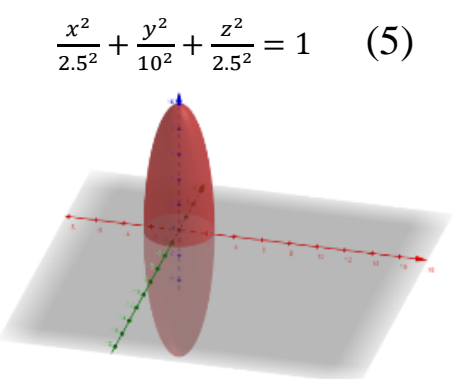

(c)

FIGURE 3. (a) simulation of prolate ellipsoid 3D in large pores, (b) simulation of prolate ellipsoid 3D in medium pore, (c) 3D simulation of ellipsoid prolate in small pores [28].

Furthermore, the expected pore volume was done by cutting into 2 equal parts into a double decomposed ellipsoid as in FIGURE,4. In each simulated pore hole, the diameter is illustrated in the range of $5 \mu \mathrm{m}$ to $10 \mu \mathrm{m}$, and the pore depth is $10 \mu \mathrm{m}$ as illustrated in FIGURE. 4.
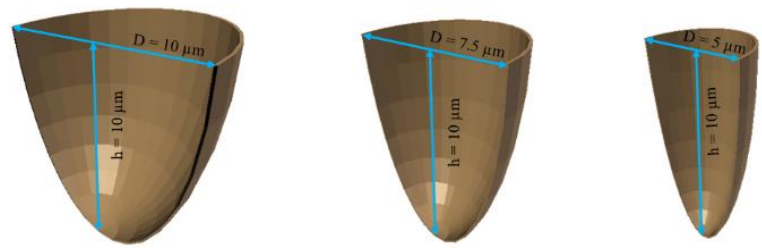

FIGURE 4. Illustration of a range of pore holes in human skin from small to largest.

The volume equation of the plane can find the volume of the truncated prolate rotated on the $y$-axis as follows [29].

$$
\begin{aligned}
& \mathrm{V}=\int_{c}^{d} A(\mathrm{y}) \mathrm{dy} \\
& \mathrm{V}=\int_{c}^{d} \pi[R(y)]^{2} d y \\
& \mathrm{~V} \text { Prolate }=\int_{-10}^{0} \pi[R(y)]^{2} d y
\end{aligned}
$$


The volume was calculated using EQUATION 11, and the VProlate pore volume was identified in TABLE 3

TABLE 3. Volume of Prolate

\begin{tabular}{llllll}
\hline Skin Pore & $\mathbf{r}_{\mathbf{x}}(\boldsymbol{\mu} \mathbf{m})$ & $\mathbf{r}_{\mathbf{y}}(\boldsymbol{\mu} \mathbf{m})$ & $\mathbf{r}_{\mathbf{z}}(\boldsymbol{\mu} \mathbf{m})$ & $V_{\text {Prolate }}\left(\boldsymbol{\mu \mathbf { m } ^ { 3 }}\right)$ & $\mathbf{V}_{\text {A Half Prolate }}\left(\boldsymbol{\mu \mathbf { m } ^ { 3 }}\right)$ \\
\hline Big & 5.00 & 5.00 & 10.00 & 1047.62 & 523.81 \\
Medium & 3.75 & 3.75 & 10.00 & 589.29 & 294.64 \\
Small & 2.50 & 2.50 & 10.00 & 261.90 & 130.95 \\
\hline
\end{tabular}

\section{Moisturizer Skin}

Moisturizing the skin is the most fundamental aspect of human hygiene, which affects health and skin disease [30]. A functioning stratum corneum (SC) is essential for healthy skin [31]. To maintain integrity, SC uses a number of natural systems to store water in the skin [14]. The primary purpose of developing moisturizers is to restore lipids to the surface of the skin after cleaning. In recent developments, moisturizers have been developed to distribute active ingredients cosmetics [32-34].

Moisturizers must meet four essential needs so that the interests of consumers: make skin smooth and soft, increase skin hydration, improve appearance, and possibly send ingredients to the surface of the skin [30]. Dry skin or xeroderma is a widespread problem that can be caused by complex interactions between environmental and individual factors [35]. Xerosis, xeroderma, asteatosis, and "winter itch" have all been used as synonyms for dry skin.

Epidermal hydration is determined by the non-invasive use of electronic devices, a multitester that measures resistance based on the well-known fact that hydrated skin has less resistance to current flow than dehydrated skin. The level of hydration of the stratum corneum is assessed by measuring changes in skin resistance and is referred to as galvanic skin response or electric skin resistance. The reported skin resistance in ohms with electrodes $\left[1 \mathrm{~cm}^{2}\right.$ size $]$ was measured 30 minutes and 6 hours after application of the formulation [continuous for up to 3 weeks] at $1000 \mathrm{kHz}, 10 \mathrm{~mA}, \mathrm{AC}$ current [36].

Skin characteristics such as moisture, mechanical flexibility, and skin taste can be improved with several personal care products. These products contain moisturizers, occlusive; lubricant; emollients to improve texture, rubbing, and softness, and fragrances to increase consumer acceptance of the product. Moisturizers as a class include humectants and occlusions. Humectants are substances that, when absorbed, help the skin retain moisture, thus making the skin more supple and softer. Common humectants include glycerin, propylene glycol, pyrrolidone carboxylic acid, sodium lactate, urea, and certain natural lipid mixtures [37].

In this study, the moisturizer category used is lotion. Lotions are emulsions containing hydrophilic and hydrophobic ingredients. Oil-in-water $(\mathrm{O} / \mathrm{W})$ emulsions are the most popular for moisturizer use; however, emulsifiers are responsible for many of the problems associated with moisturizers as they can also solubilize intercellular lipids [30].

Moisturizers can make the skin feel smoother, a property known as emoliation. Cracks and crevices between desquamated corneocytes are filled with moisturizers, thereby reducing the quality of rough skin. Moisturizers also reduce skin friction, increase lubrication $[38,39]$. The right time and method for using moisturizers play an important role in optimal efficacy [40]. 
TABLE 4. Moisturizer selection based on skin type and location [30].

\begin{tabular}{llll}
\hline $\begin{array}{l}\text { Moisturizer } \\
\text { category }\end{array}$ & Formulation characteristics & Skin type suitability & Unique attributes \\
\hline Lotion & $\begin{array}{l}\text { The thinner film, the oil-in- } \\
\text { water emulsion. }\end{array}$ & $\begin{array}{l}\text { Face and body; normal } \\
\text { skin. }\end{array}$ & $\begin{array}{l}\text { Less greasy, spread } \\
\text { more easily }\end{array}$ \\
\hline Cream & $\begin{array}{l}\text { The thicker film, the oil-in- } \\
\text { water emulsion. }\end{array}$ & $\begin{array}{l}\text { Face, body, hands, feet; } \\
\text { dry skin. }\end{array}$ & $\begin{array}{l}\text { Higher viscosity than lotions, } \\
\text { harder to spread }\end{array}$ \\
\hline Ointment & $\begin{array}{l}\text { The thickest film contains no } \\
\text { water. }\end{array}$ & $\begin{array}{l}\text { Hands and feet; barrier } \\
\text { disrupted diseased skin. }\end{array}$ & $\begin{array}{l}\text { Greasy, sticky; based on } \\
\text { petrolatum, lanolin, dimethicone }\end{array}$ \\
\hline Paste & $\begin{array}{l}\text { Ointment mixed with powder } \\
\text { contains no water }\end{array}$ & Diaper area & $\begin{array}{l}\text { Greasy, sticky, resists water } \\
\text { removal; based on zinc oxide and } \\
\text { petrolatum. }\end{array}$ \\
\hline Gel & $\begin{array}{l}\text { Thick until rubbed into the skin, } \\
\text { then flowable }\end{array}$ & Face, hair & $\begin{array}{l}\text { Leave nongreasy film; based on } \\
\text { acrylic polymers, gums, and } \\
\text { cellulose thickeners. }\end{array}$ \\
\hline Serum & $\begin{array}{l}\text { Thin liquid to deliver } \\
\text { Cosmetic ingredients to the skin }\end{array}$ & Face & $\begin{array}{l}\text { The minimal film, rapid } \\
\text { evaporation, nongreasy. }\end{array}$ \\
\hline Powder & $\begin{array}{l}\text { Blended small particle solid } \\
\text { materials }\end{array}$ & $\begin{array}{l}\text { Intertriginous areas; foot } \\
\text { powder, diaper powder }\end{array}$ & $\begin{array}{l}\text { Absorbs water; based on talc, } \\
\text { silicates, and starch. }\end{array}$ \\
\hline Suspension & $\begin{array}{l}\text { Clear liquid with } \\
\text { visible particles }\end{array}$ & $\begin{array}{l}\text { Oily skin, intertriginous } \\
\text { areas }\end{array}$ & $\begin{array}{l}\text { Liquid powder; based on } \\
\text { carbomer, bentonite clay. }\end{array}$ \\
\hline Stick & $\begin{array}{l}\text { Solid stroked over skin to leave } \\
\text { film contains no water }\end{array}$ & Lips & $\begin{array}{l}\text { Melts at body temperature to a } \\
\text { film; based on paraffin, } \\
\text { candelilla, and carnauba wax. }\end{array}$ \\
\hline Aerosol & $\begin{array}{l}\text { Droplet film; requires can, } \\
\text { propellant, and nozzle }\end{array}$ & Hair-bearing skin & $\begin{array}{l}\text { Inefficient discontinuous film } \\
\text { application. }\end{array}$ \\
\hline & & &
\end{tabular}

\section{RESULTS AND DISCUSSION}

A large collection of non-overlapping solid (particle) solids in the Euclidean space Ddimensional $\mathrm{R}^{\mathrm{d}}$ called packing. The packing density $\varphi$ is defined as the fraction of $\mathrm{R}^{\mathrm{d}}$ space covered by the particles. The problem that has been a source of attraction for mathematicians and scientists for centuries is the determination of the densest arrangement of particles that do not go out of space and reach a maximum density of $\varphi[22]$.

Lattice in a 3-Dimensional Space $\mathrm{R}^{3}$ is an infinite set of points generated by a set of discrete translation operations (defined by a linear integer combination based on Dimension Three $\mathrm{R}^{3}$ ). Lattice packing is packaging where the center of mass of non-overlapping particles is located at the center of the lattice, each oriented in the same direction. The three-dimensional Space $\mathrm{R}^{3}$ can then be geometrically divided into identical regions of $\mathrm{F}$ called fundamental cells (Granular simulated as fundamental cells in this study), each of which contains only the center of mass of one particle. Thus, the number of granules in the container is given by EQUATION 12 and $13[22,41]$.

$$
\begin{aligned}
& k_{\text {max }}=\frac{V_{\text {oblate }}}{V_{\text {Particle }}} \varphi \\
& k_{\text {max }} \leq \frac{\frac{4}{3} \pi a^{2} b}{\frac{4}{3} \pi r^{3}} \varphi
\end{aligned}
$$

where Voblate is the volume of a particle, and VParticle is the volume of a fundamental cell and packing density $\varphi(\varphi=0.64$ (Close random packing)) that show in TABLE 5 . 
Based on theoretical calculations, simulations are performed using granular on porous surfaces. This simulation demonstrates a granular attachment to a dry and mois porous system. Granules that are simulated fall will be done in 5 different sizes; $1 \mu \mathrm{m}, 2 \mu \mathrm{m}, 3 \mu \mathrm{m}, 4 \mu \mathrm{m}$, and $5 \mu \mathrm{m}$. Whereas pore simulated has 3 different sizes; $5 \mu \mathrm{m}, 7.5 \mu \mathrm{m}$, and $10 \mu \mathrm{m}$ in diameter (TABLE 5).

TABLE 5. Comparison between volume of pore and particle in theory.

\begin{tabular}{lllll}
\hline Pore & Granular $(\mu \mathrm{m})$ & $\mathrm{V}_{\text {Oblate }}$ & $\mathrm{V}_{\text {Particle }}$ & $\mathrm{k}_{\max }$ \\
\hline Big & 1 & 523.81 & 0.52381 & 640.00 \\
& 2 & 523.81 & 4.19048 & 80.00 \\
& 3 & 523.81 & 14.14286 & 23.70 \\
& 4 & 523.81 & 33.52381 & 10.00 \\
\hline \multirow{2}{*}{ Medium } & 5 & 523.81 & 65.47619 & 5.12 \\
& 1 & 294.64 & 0.52381 & 360.00 \\
& 3 & 294.64 & 4.19048 & 45.00 \\
& 4 & 294.64 & 14.14286 & 13.33 \\
& 5 & 294.64 & 33.52381 & 5.62 \\
Small & 1 & 294.64 & 65.47619 & 2.88 \\
& 2 & 130.95 & 0.52381 & 160.00 \\
& 3 & 130.95 & 4.19048 & 20.00 \\
& 4 & 130.95 & 14.14286 & 5.92 \\
& 5 & 130.95 & 33.52381 & 2.50 \\
\hline
\end{tabular}

In the next step, the skin and the granular simulated using Unity3D. FIGURE. 5 simulates the final condition of $1 \mu \mathrm{m}$ granular attachment on a porous surface.

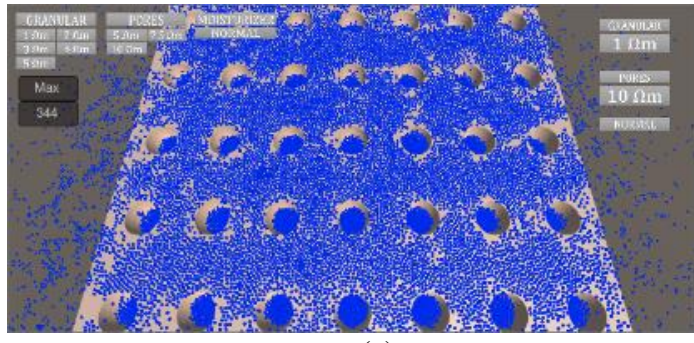

(a)

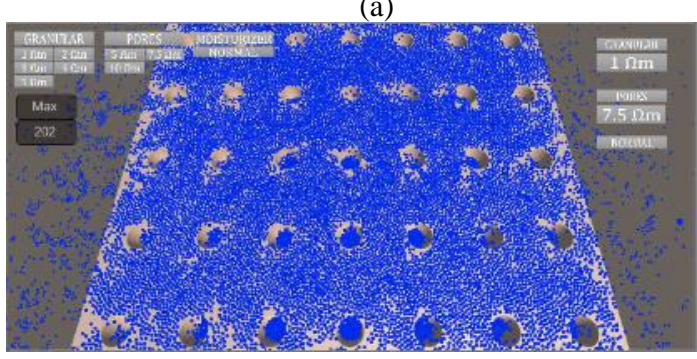

(c)

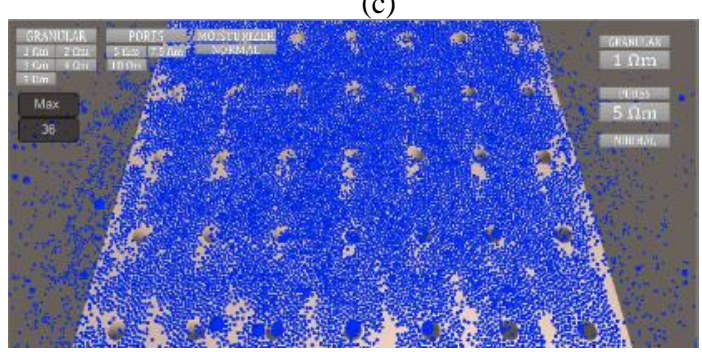

(e)

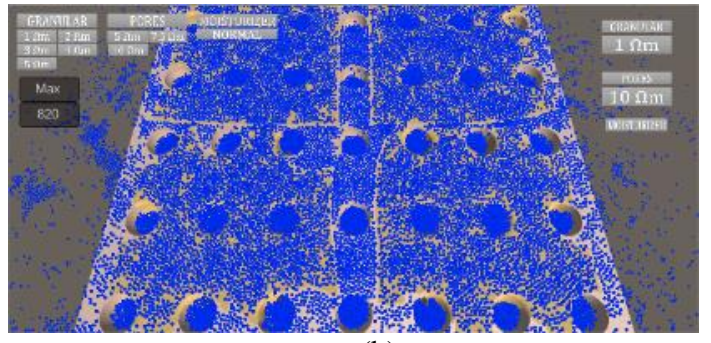

(b)

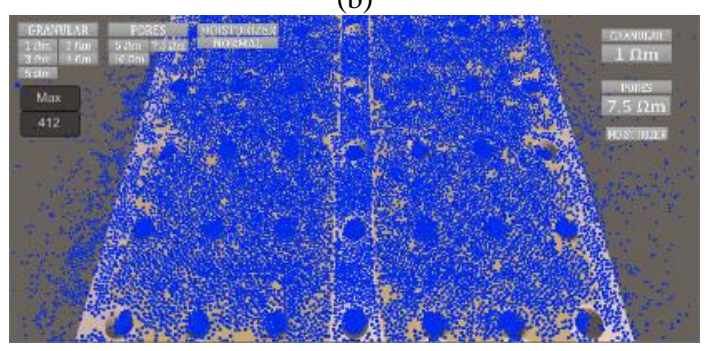

(d)

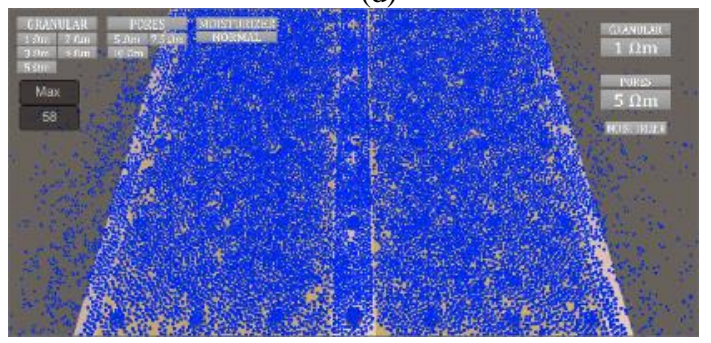

(f)

FIGURE 5. Attaching Granules $1 \mu \mathrm{m}$ to the surface; (a) $10 \mu \mathrm{m}$ porous surface simulation on dry skin, (b) simulation of a $10 \mu \mathrm{m}$ porous surface on moist skin, (c) $7.5 \mu \mathrm{m}$ porous surface simulation on dry skin, (d) 7.5 $\mu \mathrm{m}$ porous surface simulation on moist skin, (e) $5 \mu \mathrm{m}$ porous surface simulation on dry skin, (f) $5 \mu \mathrm{m}$ porous surface simulation on moist skin. 
TABLE 6. Number of $1 \mu \mathrm{m}$ Granul in Pore

\begin{tabular}{llll}
\hline Granular Diameter & Pore Diameter & Dry Skin & Moister Skin \\
\hline \multirow{3}{*}{$1 \mu \mathrm{m}$} & $10 \mu \mathrm{m}$ & 344 & 820 \\
& $7.5 \mu \mathrm{m}$ & 202 & 412 \\
& $5 \mu \mathrm{m}$ & 36 & 58 \\
\hline
\end{tabular}

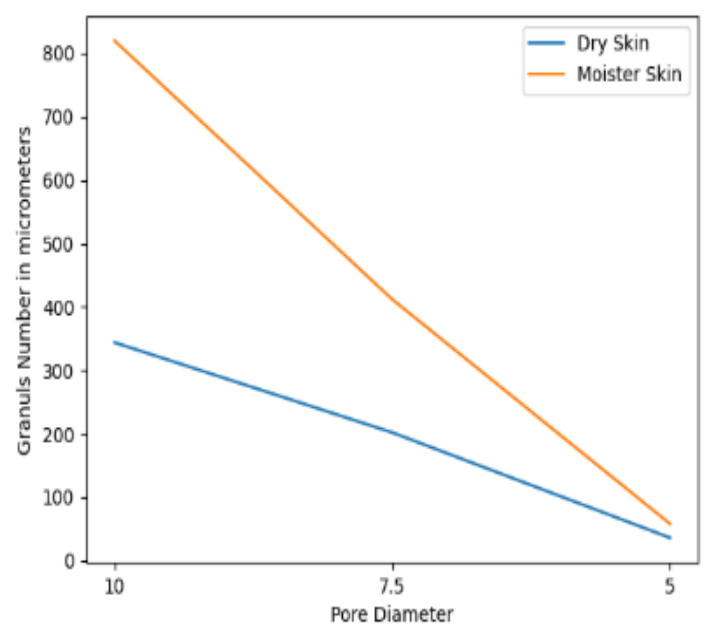

FIGURE 6. Graphs of the number of $1 \mu \mathrm{m}$ granular in pores

From the data in FIGURE 5, FIGURE 6 and TABLE 6 show that the amount of granular attachment is directly proportional to the size of the porous surface and moisturizer causing more granular attachment. Granular seems to stick more to the larger porous surface, because the basin does have a larger volume. FIGURE 7, FIGURE 8 and TABLE 7 simulate the final condition of $2 \mu \mathrm{m}$ granular attachment on a porous surface.

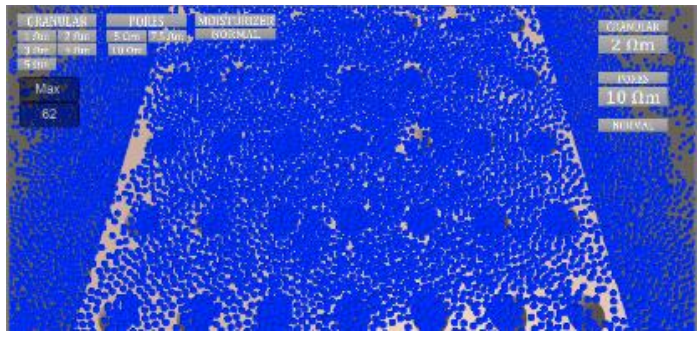

(a)

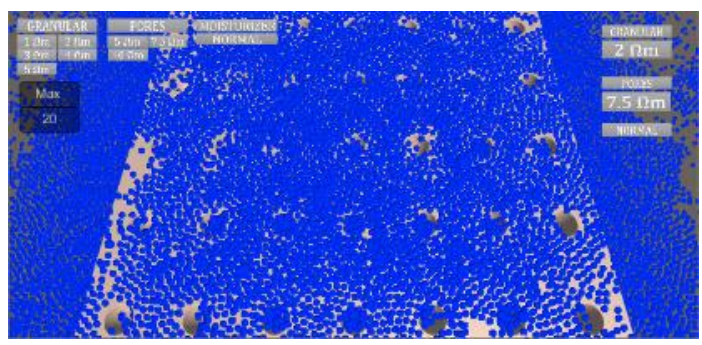

(c)

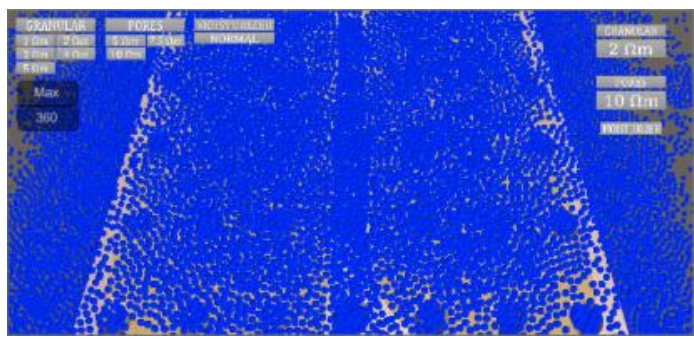

(b)

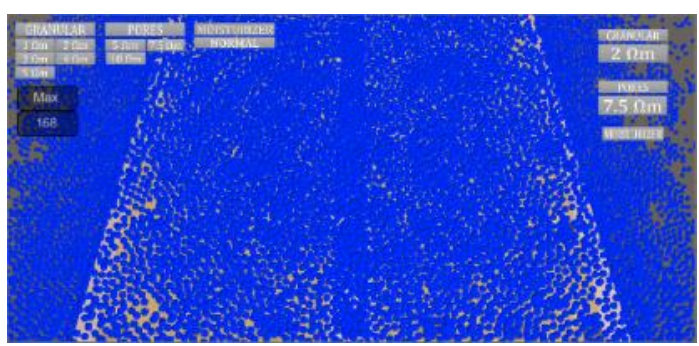

(d) 


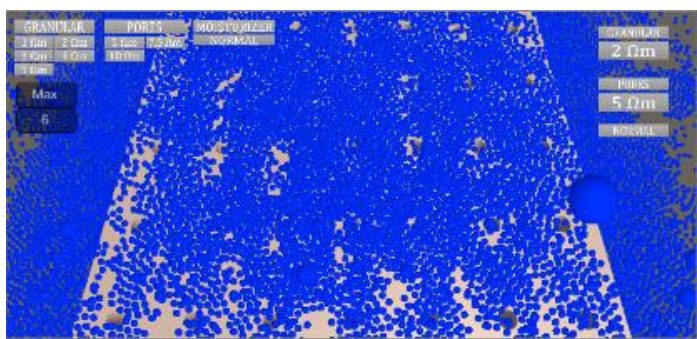

(e)

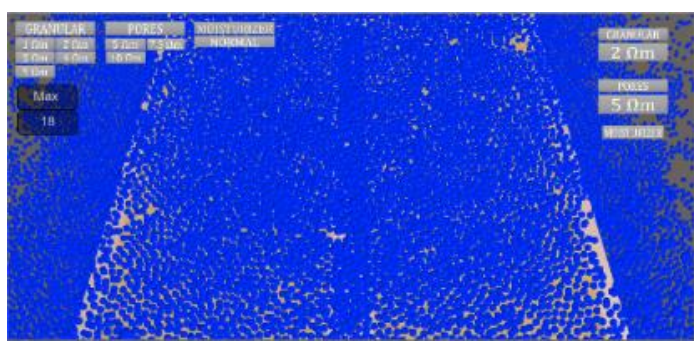

(f)

FIGURE 7. Attaching Granules $2 \mu \mathrm{m}$ to the surface; (a) $10 \mu \mathrm{m}$ porous surface simulation on dry skin, (b) simulation of a $10 \mu \mathrm{m}$ porous surface on moist skin, (c) $7.5 \mu \mathrm{m}$ porous surface simulation on dry skin, (d) 7.5 $\mu \mathrm{m}$ porous surface simulation on moist skin, (e) $5 \mu \mathrm{m}$ porous surface simulation on dry skin, (f) $5 \mu \mathrm{m}$ porous surface simulation on moist skin.

TABLE 7. Number of $2 \mu \mathrm{m}$ Granul in Pore

\begin{tabular}{llll}
\hline Granular Diameter & Pore Diameter & Dry Skin & Moister Skin \\
\hline \multirow{2}{*}{$2 \mu \mathrm{m}$} & $10 \mu \mathrm{m}$ & 62 & 360 \\
& $7.5 \mu \mathrm{m}$ & 20 & 168 \\
& $5 \mu \mathrm{m}$ & 6 & 18 \\
\hline
\end{tabular}

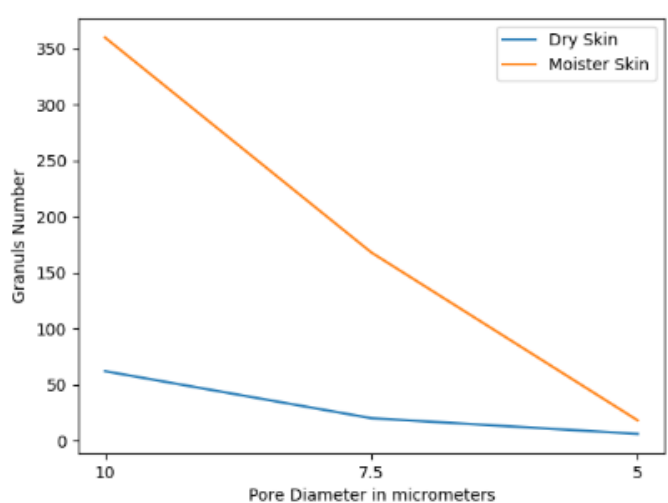

FIGURE 8. Graphs of the number of $2 \mu \mathrm{m}$ granular in pores

From the data in FIGURE 7 shows that the amount of granular attachment is directly proportional to the size of the porous surface.

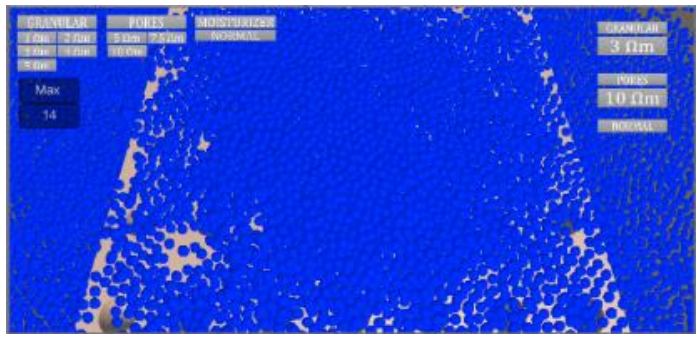

(a)

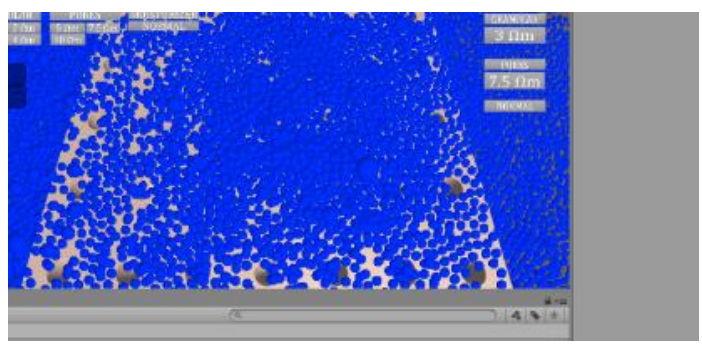

(c)

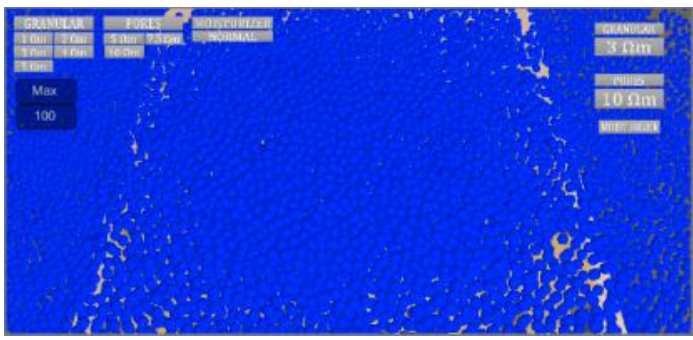

(b)

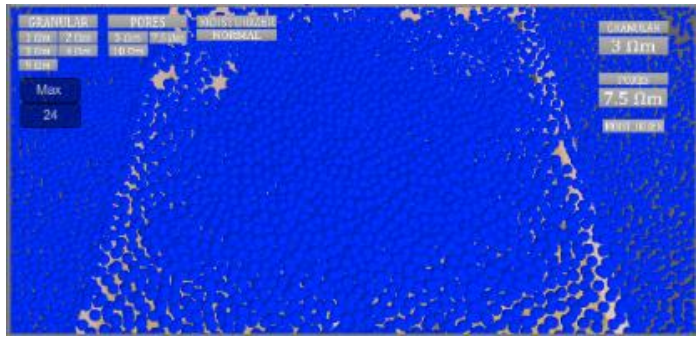

(d) 


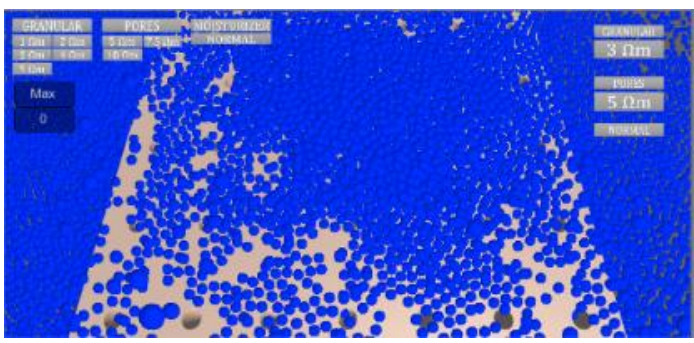

(e)

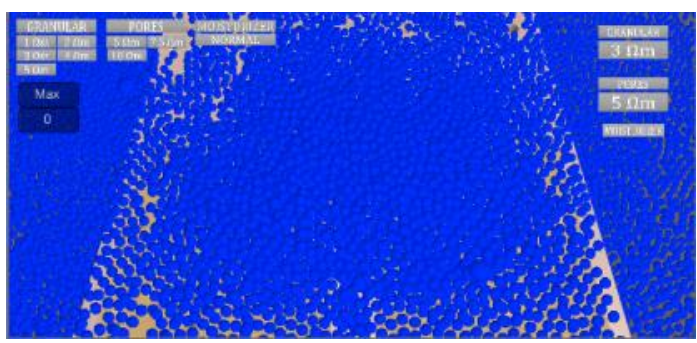

(f)

FIGURE 9. Attaching Granules $3 \mu \mathrm{m}$ to the surface; (a) $10 \mu \mathrm{m}$ porous surface simulation on dry skin, (b) simulation of a $10 \mu \mathrm{m}$ porous surface on moist skin, (c) $7.5 \mu \mathrm{m}$ porous surface simulation on dry skin, (d) 7.5 $\mu \mathrm{m}$ porous surface simulation on moist skin, (e) $5 \mu \mathrm{m}$ porous surface simulation on dry skin, (f) $5 \mu \mathrm{m}$ porous surface simulation on moist skin.

TABLE 8. Number of $3 \mu \mathrm{m}$ Granul in Pore

\begin{tabular}{llll}
\hline Granular Diameter & Pore Diameter & Dry Skin & Moister Skin \\
\hline \multirow{3}{*}{$3 \mu \mathrm{m}$} & $10 \mu \mathrm{m}$ & 14 & 100 \\
& $7.5 \mu \mathrm{m}$ & 0 & 24 \\
& $5 \mu \mathrm{m}$ & 0 & 0 \\
\hline
\end{tabular}

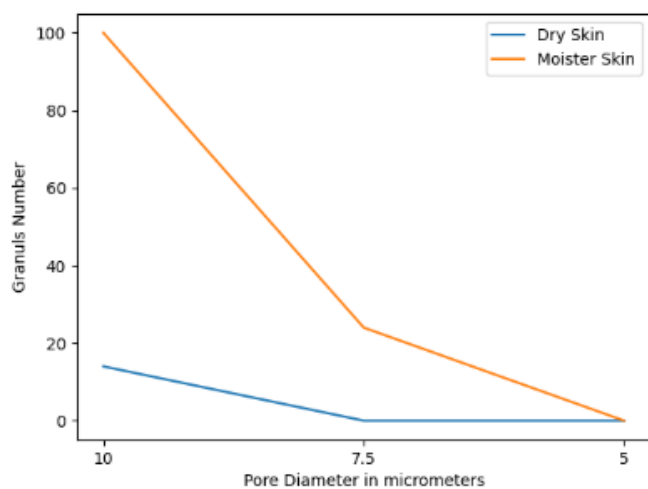

FIGURE 10. Graphs of the number of $3 \mu \mathrm{m}$ granular in pores.

FIGURE 9 simulates the final condition of $3 \mu \mathrm{m}$ granular attachment on a porous surface. From the data in FIGURE 9, TABLE 8 shows that the amount of granular attachment is directly proportional to the size of the porous surface.

FIGURE 11, FIGURE 12 and TABLE 9 simulate the final condition of a $4 \mu \mathrm{m}$ granular attachment on a porous surface.

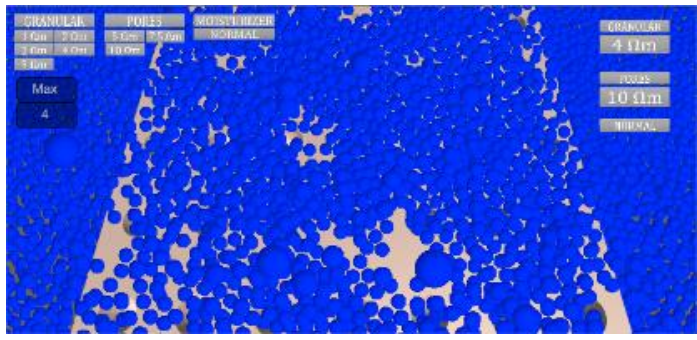

(a)

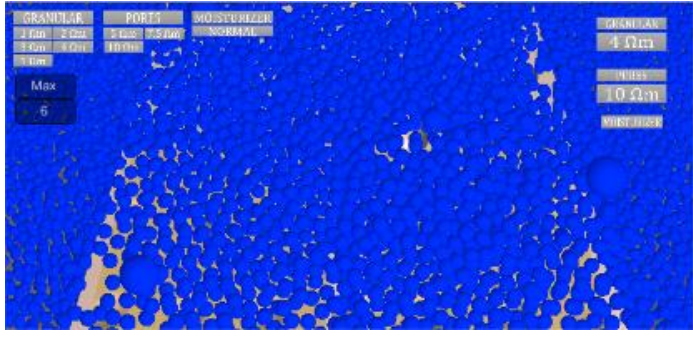

(b) 


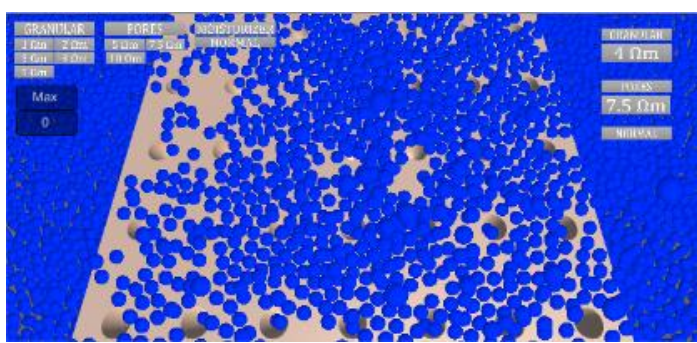

(c)

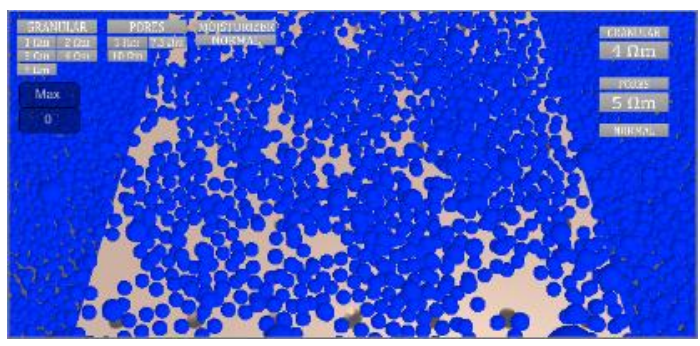

(e)

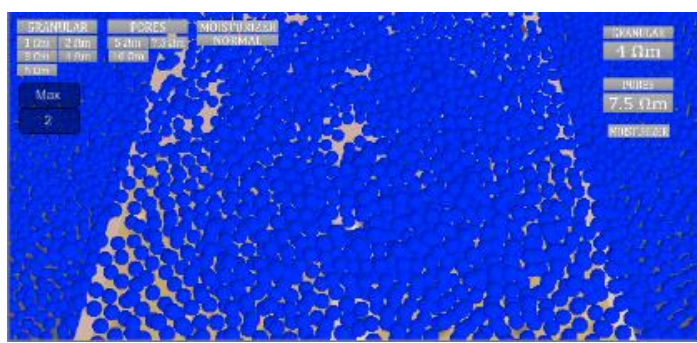

(d)

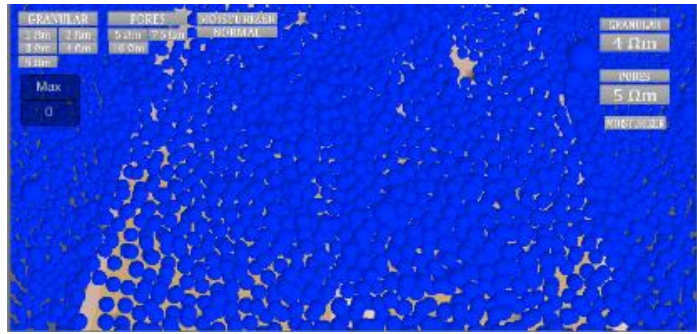

(f)

FIGURE 11. Attaching Granules $4 \mu \mathrm{m}$ to the surface; (a) $10 \mu \mathrm{m}$ porous surface simulation on dry skin, (b) simulation of a $10 \mu \mathrm{m}$ porous surface on moist skin, (c) $7.5 \mu \mathrm{m}$ porous surface simulation on dry skin, (d) 7.5 $\mu \mathrm{m}$ porous surface simulation on moist skin, (e) $5 \mu \mathrm{m}$ porous surface simulation on dry skin, (f) $5 \mu \mathrm{m}$ porous surface simulation on moist skin.

TABLE 9. Number of $4 \mu \mathrm{m}$ Granul in Pore

\begin{tabular}{llll}
\hline Granular Diameter & Pore Diameter & Dry Skin & Moister Skin \\
\hline \multirow{3}{*}{$4 \mu \mathrm{m}$} & $10 \mu \mathrm{m}$ & 4 & 6 \\
& $7.5 \mu \mathrm{m}$ & 0 & 2 \\
& $5 \mu \mathrm{m}$ & 0 & 0 \\
\hline
\end{tabular}

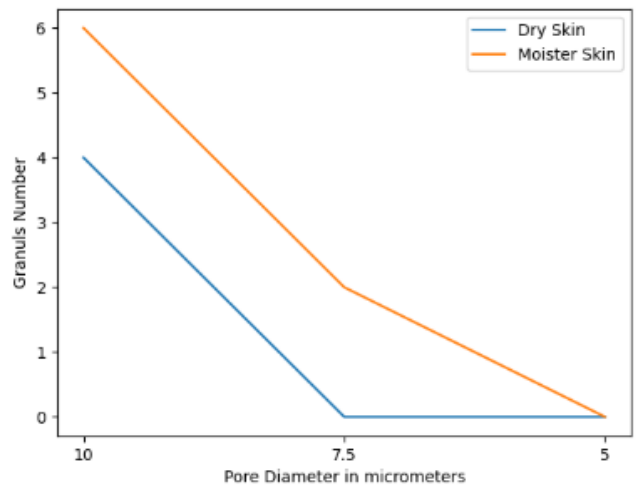

FIGURE 12. Graphs of the number of $4 \mu \mathrm{m}$ granular in pores

From the data FIGURE 11 and FIGURE 12 show that the amount of granular attachment is directly proportional to the size of the porous surface.

It can be analyzed in FIGURE 13 to simulate the final conditions of a $5 \mu \mathrm{m}$ granular attachment to a porous surface based on Data in TABLE 10. 


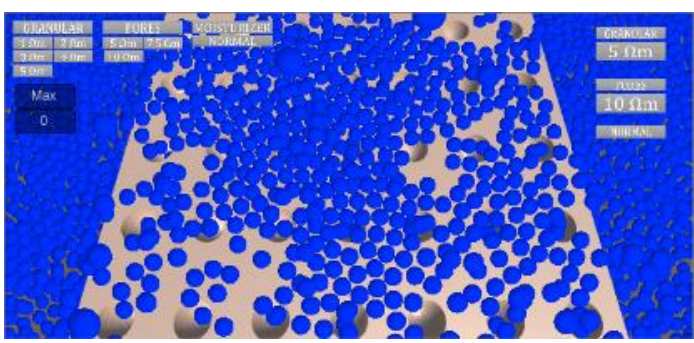

(a)

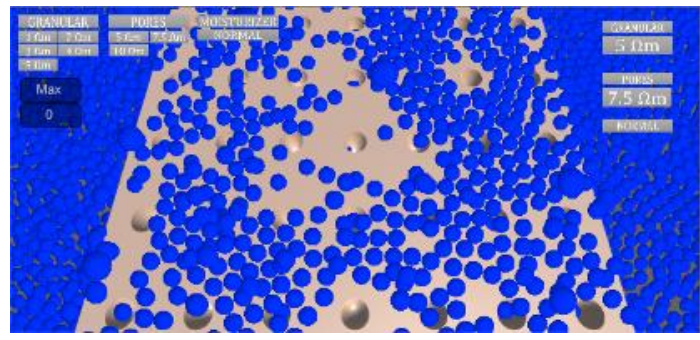

(c)

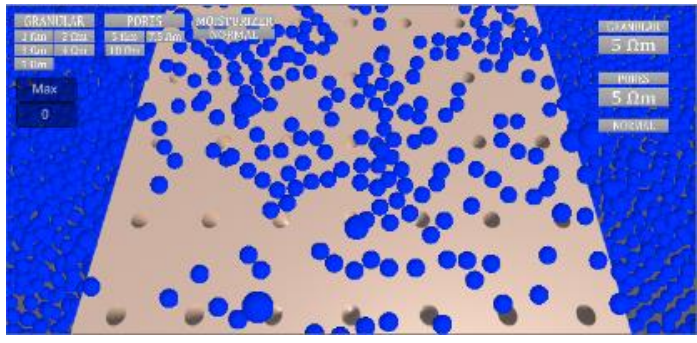

(e)

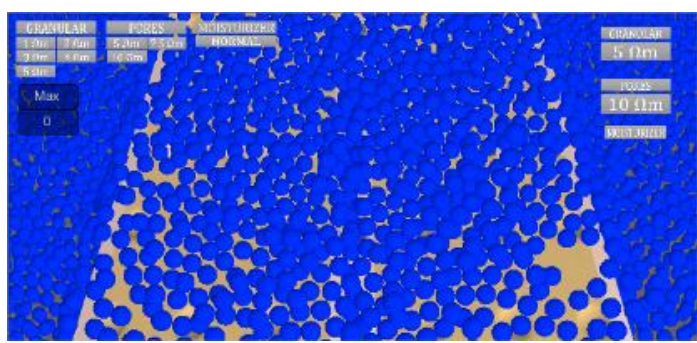

(b)

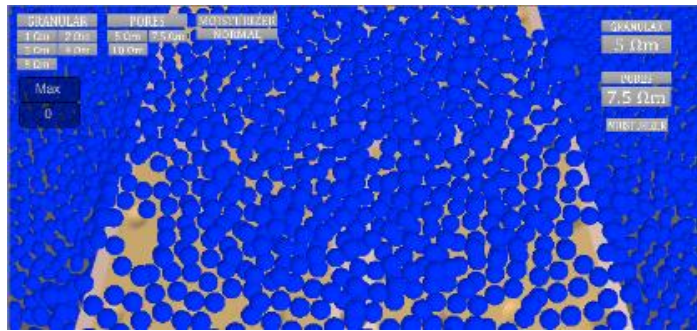

(d)

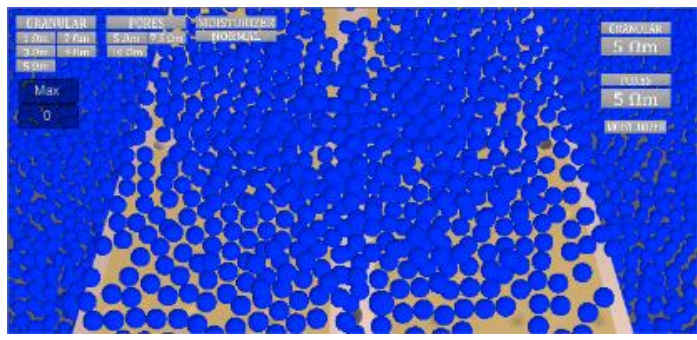

(f)

FIGURE 13. Attaching Granules $5 \mu \mathrm{m}$ to the surface; (a) $10 \mu \mathrm{m}$ porous surface simulation on dry skin, (b) simulation of a $10 \mu \mathrm{m}$ porous surface on moist skin, (c) $7.5 \mu \mathrm{m}$ porous surface simulation on dry skin, (d) 7.5 $\mu \mathrm{m}$ porous surface simulation on moist skin, (e) $5 \mu \mathrm{m}$ porous surface simulation on dry skin, (f) $5 \mu \mathrm{m}$ porous surface simulation on moist skin.

TABLE 10. Number $5 \mu \mathrm{m}$ Granul in Pore

\begin{tabular}{llll}
\hline Granular Diameter & Pore Diameter & Dry Skin & Moister Skin \\
\hline \multirow{3}{*}{$5 \mu \mathrm{m}$} & $10 \mu \mathrm{m}$ & 0 & 0 \\
& $7.5 \mu \mathrm{m}$ & 0 & 0 \\
\hline
\end{tabular}

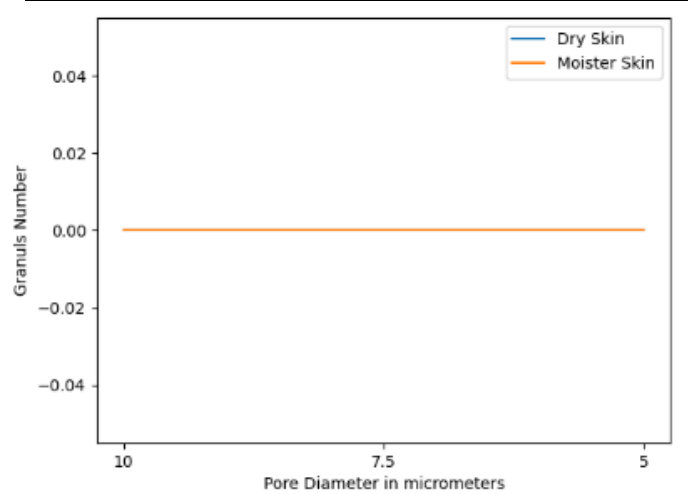

FIGURE 14. Graphs of the number of $5 \mu \mathrm{m}$ granular in pores 
From the data in FIGURE 14 shows that the number of granular attachments of the three pores identifies the number zero. The simulation in FIGURE 13 produces a zero due to a large coefficient of restitution so that when it enters the pore, the granular will be reflected back. This situation is caused by the skin being too dry when using cosmetics, to handle this, a moisturizer is needed in stages which make the coefficient of restitution as small as possible, so that it can accept the sticking of cosmetics. When compared with the calculation of theory sphere packing and simulation results, the data in TABLE 11.

TABLE 11. The comparison of theory sphere packing and simulation results.

\begin{tabular}{|c|c|c|c|c|}
\hline \multirow{2}{*}{ Granular Diameter } & \multirow{2}{*}{ Pore Diameter } & \multirow{2}{*}{$\mathbf{K}_{\text {Theory }}$} & \multicolumn{2}{|c|}{$\mathrm{K}_{\text {Simulation }}$} \\
\hline & & & $\mathbf{K}_{\text {Dry Skin }}$ & $\mathbf{K}_{\text {Mois Skin }}$ \\
\hline \multirow{3}{*}{$1 \mu m$} & $10 \mu \mathrm{m}$ & 640 & 344 & 820 \\
\hline & $7.5 \mu \mathrm{m}$ & 360 & 202 & 412 \\
\hline & $5 \mu m$ & 160 & 36 & 58 \\
\hline \multirow{3}{*}{$2 \mu m$} & $10 \mu \mathrm{m}$ & 80 & 62 & 360 \\
\hline & $7.5 \mu \mathrm{m}$ & 45 & 20 & 168 \\
\hline & $5 \mu m$ & 20 & 6 & 18 \\
\hline \multirow{3}{*}{$3 \mu m$} & $10 \mu m$ & 23.7037 & 14 & 100 \\
\hline & $7.5 \mu \mathrm{m}$ & 13.33333 & 0 & 24 \\
\hline & $5 \mu m$ & 5.925926 & 0 & 0 \\
\hline \multirow{3}{*}{$4 \mu m$} & $10 \mu m$ & 10 & 4 & 6 \\
\hline & $7.5 \mu \mathrm{m}$ & 5.625 & 0 & 2 \\
\hline & $5 \mu m$ & 2.5 & 0 & 0 \\
\hline \multirow{3}{*}{$5 \mu m$} & $10 \mu m$ & 5.12 & 0 & 0 \\
\hline & $7.5 \mu \mathrm{m}$ & 2.88 & 0 & 0 \\
\hline & $5 \mu m$ & 1.28 & 0 & 0 \\
\hline
\end{tabular}

If an analysis is performed on the graph, the graph in FIGURE 15 is obtained in x-axis and yaxis. These results lines with the preliminary research that show the porous hole diameter and the granular restitution coefficient influenced the particles entering the porous surface system [42].

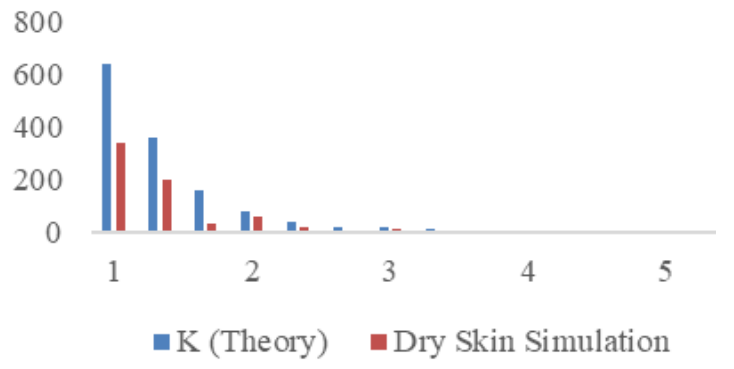

(a)

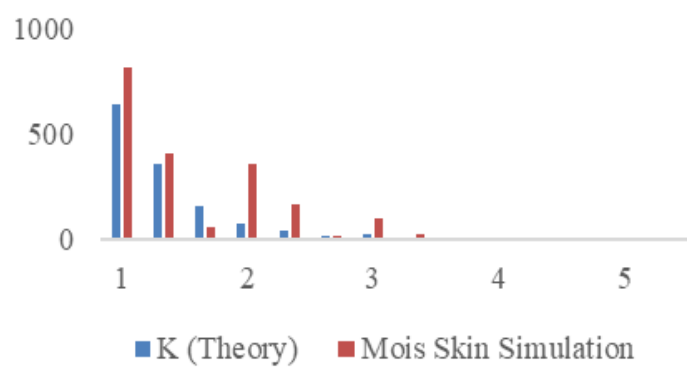

(b)

FIGURE 15. a. comparison between Moist Skin Simulation and Theory, b. Comparison between Dry Skin Simulation and Theory

Based on comparative analysis with theory, the simulation performed on dry skin is still far away from the minimum sphere packing, this is because in the cosmetic attachment that is simulated with granular there is still excessive restitution on the surface of dry skin. Further simulation is to add other moisterizer that functions as a moisturizer that minimizes restitution. With the moisterizer we get a simulation of a better cosmetic attachment than dry skin. Cosmetic attachment is easier to do by using a moisterizer because of its nature which reduces the coefficient of restitution and reduces friction. However, using moizterizer is not enough. 
There is still a mismatch between the maximum value of attachment according to simulation and theory. So it needs further research to find additional components that can reduce the coefficient of restitution in the use of cosmetics and maximize the process of applying cosmetics to the skin. In further research, this simulation must also consider the density of particles that fall earlier because if the granules overlap with each other, a granular buoyancy force will be created, which has similar characteristics to the fluid buoyancy force [43], also necessary to consider the initial velocity of the fall because the granular will experience a reverse velocity in accordance with the contact plane when it falls in the pore hole conditions [44].

\section{CONCLUSION}

A simulation of granular variations has been carried out to measure the size and variation of porous surface humidity. Simulation results show a relationship between porous surfaces and granules. The results show that the number of cosmetic granular particles entering the porous surface system is directly proportional to the porous surface volume and moisture and inversely proportional to the granular cosmetic size. In moist skin, the distribution of granules is spread homogeneously on the surface. The larger the cosmetic granular used, the less granular enter the pore. This simulation is deemed necessary to support complex research furthermore.

\section{ACKNOWLEDGMENT}

We gratefully acknowledge support from the Hibah Penelitian Terapan Fakultas MIPA Universitas Negeri Jakarta under contract year 2021. Our simulations developed in the Digital Laboratory - Physics Education Department, Universitas Negeri Jakarta.

\section{REFERENCES}

[1] S. Rémond et al., "Simulation of the packing of granular mixtures of non-convex particles and voids characterization," Granul. Matter, vol. 10, pp. 157-170, 2008.

[2] A. Sufian et al., "Pore shapes, volume distribution and orientations in monodisperse granular assemblies," Granul. Matter, vol. 17, no. 6, pp. 727-742, 2015.

[3] M. Xu et al., "DEM Simulation of The Undrained Shear Behavior of Sand Containing Dissociated Gas Hydrate,” Granul. Matter, vol. 18, no. 4, pp. 79-91, 2016.

[4] X. Ting et al., "Study of the Characteristics of the Flow Regimes and Dynamics of Coarse Particles in Pipeline Transportation," Powder Technol, vol. 347, pp. 148-158, 2019.

[5] M. Ariane et al., "Wall collision and drug-carrier detachment in dry powder inhalers : Using DEM to devise a sub-scale model for CFD calculations," Powder Technol, vol. 334, pp. 65-75, 2018.

[6] Y. Yao, "Granular Computing: Past, Present and Future," RSKT 2008 Rough Sets Knowl. Technol, vol. 5009, pp. 27-28, 2016.

[7] O. Stenzel et al., "Quantitative Structural Analysis of Simulated Granular Packings of Non-spherical Particles," Granul. Matter, vol. 16, no. 4, pp. 457-468, 2014. 
[8] F. Flament et al., "Facial skin pores : a multiethnic study," Clin. Cosmet. Investig. Dermatol, vol. 8, pp. 85-93, 2015.

[9] P. S. Prestes et al., "Particle size and morphological characterization of cosmetic emulsified systems by Optical Coherence Tomography ( OCT )," Brazilian J. Pharm. Sci, vol. 52, no. 2, pp. 273-280, 2016.

[10] Horiba, “A Guidebook To Particle Size Analysi,” Irvine, USA: HORIBA Insruments, 2017.

[11] Horiba, "Particle Size Analysis of Cosmetics," Irvine, USA: HORIBA Instruments, 2007.

[12] R. Costa, L. Santos, "Delivery systems for cosmetics - From manufacturing to the skin of natural antioxidants," Powder Technol, vol. 322, pp. 402-416, 2017.

[13] J. B. Holyoke, W. C. Lobitz, "Histologic Variations in the Structure of Human Eccrine Sweat Glands,” J. Invest. Dermatol, vol. 18, no. 2, pp. 147-167, 1952.

[14] C. R. Harding, "The Stratum Corneum: Structure and Function in Health and Disease," Dermatol. Ther, vol. 17, pp. 6-15, 2004.

[15] A. Donev, "Improving the Density of Jammed Disordered Packings Using Ellipsoids," Science, vol. 303, no. 5660, pp. 990-993, 2004.

[16] P. Erdos, R. L. Graham, "On Packing Squares with Equal Squares,” J. Comb. Theory, vol. 19, pp. 119-123, 1975.

[17] Y. G. Stoyan, G. N. Yaskov, "Packing Identical Spheres into a Cylinder," Intl. Trans. Op. Res, vol. 17, pp. 51-70, 2010.

[18] Y. Jiao et al., "Optimal Packings of Superballs," Phys. Rev. E, vol. 79, no. 041309, pp. 1-12, 2009.

[19] L. Boissieux et al., "Simulation of Skin Aging and Wrinkles with Cosmetics Insight," Comput. Animat. Simul, vol. 2000, pp. 15-27, 2000.

[20] C. Li et al., "Physically-Based Simulation of Cosmetics via Intrinsic Image Decomposition with Facial Priors," IEEE Trans. Pattern Anal. Mach. Intell, vol. 40, no. 10, pp. 1-15, 2018.

[21] W. Steiling et al., "Principles for The Safety Evaluation of Cosmetic Powders," Toxicol. Lett, vol. 297, pp. 8-18, 2018.

[22] S. Torquato, Y. Jiao, "Dense Packings of The Platonic and Archimedean Solids," Nature, vol. 460, pp. 876-879, 2009.

[23] F. A. L. Dullien, "Porous Media: Fluid Transport and Pore Structure," San Diego: Academic Press, 1992.

[24] I. Smalley, "Simple Regular Sphere Packings in Three Dimensions," Math. Mag, vol. 36, no. 5, pp. 295-300, 1963.

[25] T. Igarashi et al., "The Appearance of Human Skin,” New York: Columbia University, 2005.

[26] W. D. James et al., "Andrews' Diseases of the Skin: Clinical Dermatology," Philadelphia: Saunders, 2005. 
[27] Desmos Graphing Calculator [Computer software], Retrieved from https://www.desmos.com/calculator, 2020.

[28] GeoGebra 3D Calculator [Computer software], Retrieved from https://www.geogebra.org/classic\#3d, 2020.

[29] J. George, B. Thomas, “Calculus, Thirteenth,” Boston: Pearson Education, 2014.

[30] Z. D. Draelos, “The Science Behind Skin Care: Moisturizers,” J. Cosmet. Dermatol, vol. 17, no. 2, pp. 138-144, 2018.

[31] D. Rosso et al., "The Clinical Relevance of Maintaining The Functional Integrity of The Stratum Corneum in Both Healthy and Disease Affected Skin," J Clin Aesthet Dermatol, vol. 4, no. 9, pp. 22-42, 2011.

[32] Z. D. Draelos, "Cosmeceuticals: Efficacy and Influence on Skin Tone," Dermatol Clin, vol. 32, pp. 137-143, 2014.

[33] Z. D. Draelos, "Cosmeceuticals: Undefined, Unclassified, and Unregulated," Clin Dermatol., vol. 27, no. 5, pp. 431-434, 2009.

[34] Z. D. Draelos, "Cosmetics, Categories, and The Future," Dermatol Ther, vol. 25, no. 3, pp. 223-228, 2012.

[35] A. Sethi et al., "Moisturizers: The Slippery Road," Indian J Dermatol, vol. 61, no. 3, pp. 279-287, 2016.

[36] I. Nicander et al., "Baseline Electrical Impedance Measurements at Various Skin Sitesrelated to Age and Gender," Ski. Res. Technol, vol. 3, pp. 252-258, 1997.

[37] T. S. Spencer, "Dry Skin and Skin Moisturizers," Clin. Dermatol, vol. 6, no. 3, pp. 24$28,1988$.

[38] Z. D. Draelos, “Therapeutic Moisturizers,” Dermatol Clin, vol. 18, pp. 597-607, 2000.

[39] T. C. Flynn et al., "Dry Skin and Moisturizers," Clin. Dermatol, vol. 19, pp. 387-392, 2001.

[40] S. Purnamawati et al., "The Role of Moisturizers in Addressing Various Kinds of Dermatitis: A Review," Clin. Med. Res, vol. 15, no. 3, pp. 75-87, 2017.

[41] A. Varshney et al., "Estimating the Number of Unit Spheres Inside a Larger Sphere," Chapel Hill: University of North Carolina, 1994.

[42] D. Muliyati et al., "The 3-D visualization of the granular particle on various diameter porous surfaces,” J. Phys. Conf. Ser., vol. 1402, no. 7, p. 077026, 2019.

[43] D. Muliyati et al., "The granular buoyant force in a two-dimensional intruder-particles bed system," AIP Conference Proceedings, vol. 2169, p. 040005, 2019.

[44] D. Muliyati et al., "Simulation of granular in two dimensions: The effect of particle velocity on rigid wall boundary," MATEC Web Conf. vol. 197, p. 02001, 2018. 
